\title{
La simplicidad como proceso creativo culinario: ¿una tendencia para el turismo gastronómico en España?
}

\author{
Ainhoa Aguirregoitia-Martínez* $M^{\mathrm{a}}$ D. Fernández-Poyatos**
}

Universidad de Alicante (España)

\begin{abstract}
Resumen: Esta investigación plantea la conveniencia de abordar debates teóricos que ayuden a profundizar en el estudio de la simplicidad - resultado de un proceso creativo - como un activo en la tendencia actual de la restauración española. Para ello, se repasa la principal literatura sobre el turismo gastronómico y se abordan los conceptos de simplicidad. Después, se analizan los mensajes transmitidos por los destinos integrados en la entidad Saborea España al objeto de valorar si la simplicidad culinaria forma parte de estos. Los primeros resultados parecen corroborar que existe, en efecto, una interrelación entre los conceptos analizados y el uso de una gastronomía basada en la simplicidad -tradición, sencillez y excelencia de materias primas- que, además, sirve como un atractivo turístico.
\end{abstract}

Palabras clave: Turismo gastronómico; Simplicidad; Creatividad; Gastronomía; Tradición.

\section{Simplicity as a culinary creative process: a trend for gastronomic tourism in Spain?}

Abstract: This research raises the convenience of addressing theoretical debates that help to deepen the study of simplicity - result of a creative process - as an asset in the current trend of Spanish restoration. For that purpose, the main literature on gastronomic tourism is reviewed and the concepts of simplicity are addressed. Afterwards, the messages transmitted by the destinations integrated in the entity Taste Spain are analyzed in order to assess whether culinary simplicity is part of these. The first results seem to corroborate that there is, in fact, an interrelation between the concepts analyzed and the use of a gastronomy based on simplicity - tradition, simplicity and excellence of raw materials - which also serves as a tourist attraction.

Keywords: Gastronomy tourism; Simplicity; Creativity; Gastronomy; Tradition.

\section{Introducción}

La constante y acelerada exposición de novedades gastronómicas que se ofrecen en España se torna en ocasiones bastante incompatible con la reflexión y el estudio del arte culinario; desde hace aproximadamente una década, nos hallamos ante un panorama en el que cocineros y cocineras presentan a la sociedad nuevas y continuas propuestas gastronómicas de forma algo frenética, con la dificultad que ello implica para la asimilación, el asentamiento y el estudio por parte de consumidores, estudiosos o aficionados gastrónomos que, inmersos en la era de la modernidad tardía (Giddens, 1991), transitan en lo que Bauman (2007) describió como "tiempos líquidos", donde el mundo avanza a gran velocidad, las estructuras sociales no perduran el tiempo suficiente y el consumo — rápido e inmediato— se impregna de una creciente caducidad (Stringfellow et alter, 2013).

Si bien el alcance ideal de dichas novedades no debería estar condicionado o restringido por el nivel cultural —no hay por qué analizarlas, sino simplemente consumirlas y disfrutarlas—, también lo es que un público con más cultura culinaria (con toda la complejidad y debate que suscita el término) debería

Colaboradora-investigadora en el grupo de Estudios sobre publicidad institucional, política y social. Universidad de Alicante (España); E-mail: aguirregoitia.ainhoa@gmail.com

** Profesora Titular del Departamento de Comunicación y Psicología Social. Universidad de Alicante (España); E-mail: dolores.fernandez@ua.es 
ser capaz de plantear de forma más crítica y exigente fisuras o errores en las elaboraciones creadas o degustadas. Sin duda, esto haría que los profesionales de la cocina se volvieran más rigurosos y comprometidos con su trabajo, lo que se traduciría en una propuesta de mejor calidad, con más perspectivas de futuro y, sobre todo, con la posibilidad de erigirse en un notorio elemento de atracción turístico.

Este trabajo tiene como objetivo plantear una reflexión de carácter transversal —atañe a distintos ámbitos de estudio como el arte- en torno al área de conocimiento de la gastronomía y el turismo; una reflexión que ayude a profundizar en el estudio del arte gastronómico; para ello, se considera la simplicidad - resultado de un proceso creativo - como un notable activo en la actual restauración española así como en un atractivo turístico para el viajero gastrónomo. En particular, se presentan los resultados de una reflexión y un análisis interdisciplinar vinculados a la simplicidad y la creatividad, imprescindibles en el desarrollo de la gastronomía española, lo que redundaría en un incremento de valor para el turismo gastronómico.

\subsection{Turismo y gastronomía}

El turismo ha sido un sector fundamental para España desde mediados del siglo XX; sin embargo, su importancia bien se comprendió a principios del siglo, cuando el Real Decreto de 1905 lo reconoció como una fuente de ingresos esencial que llegó en el año 2017 a suponer el 14,9\% del PIB, y cuyo crecimiento interanual se ha previsto en torno al $2,7 \%$ para el año siguiente (datos provisionales) ${ }^{1}$.

Como largamente se ha declarado, primero fue el turismo de sol y playa que, tras décadas de predominio, comenzó a dar síntomas de agotamiento como exclusiva propuesta turística a finales del pasado siglo, lo que supuso que se plantearan otras modalidades que existieron en su origen, pero que se encontraban relegadas. Fue este el caso del turismo cultural que, a partir de entonces, empezó como una segunda generación y una excelente oportunidad de diversificación y desestacionalización para investigadores y planificadores. Las motivaciones de los turistas iban cambiando y la demanda del mercado turístico ponía de relieve una tendencia que perdura hasta nuestros días: los consumidores buscan vacaciones, ocio, entretenimiento y viajes más variados, donde la oferta principal esté enriquecida con otros productos, de manera que entre finales del siglo XX y principios del XXI la evolución del mercado turístico ha supuesto una segmentación cada vez mayor y más marcada: las estrategias de diversificación del producto turístico (Leal, 2011) y la lucha contra la estacionalización de la oferta turística han sido esenciales para la mejora de la competitividad de los destinos (García \& Alburquerque, 2003). Precisamente, el turismo cultural es uno de los productos que más se ha potenciado, en aras de hacer más atractiva la oferta a los consumidores.

En esta modalidad turística, otros elementos patrimoniales se han sumado recientemente: el industrial, el fotográfico, el arqueológico subacuático y el patrimonio cultural inmaterial, del que las formas de alimentación son uno de sus ámbitos de estudio. Desde esta perspectiva, la gastronomía puede integrarse en el patrimonio cultural, en particular en el etnográfico, formado por otras manifestaciones como la artesanía, los rituales festivos, la religiosidad popular... (Fernández \& Ramos, 2010). Lo que parece cabal si acordamos que el patrimonio cultural ha de entenderse como un concepto cambiante, tal y como se refleja en las diferentes definiciones desde su origen — cuando predominaban los valores artísticos - hasta la actualidad, cuando se integran los paisajes, el patrimonio bibliográfico y documental, el científico, el etnográfico, el gastronómico... (Espeteix, 2004).

Y a pesar de que la investigación académica se ha ido interesando cada vez más por cuestiones culinarias dentro del ámbito turístico, hay que reconocer que el nexo entre turismo y gastronomía es uno de los aspectos menos estudiados de manera analítica, tanto desde la perspectiva de la gastronomía como desde la del turismo (Medina, 2017; Sengel et alter, 2015): pocos libros colectivos, algunas monografías y dosieres monográficos de revistas científicas han tratado el tema, sobre todo en habla inglesa. Por su parte, Ellis et alter (2018) identifican una literatura académica en este campo dominada por cinco temas de trabajo: la motivación, la cultura, la gestión y marketing, la orientación al destino y la autenticidad. Incluso, algunos autores reivindican para el turismo un área de investigación culinaria por derecho propio.

En la actualidad, el turismo gastronómico constituye por sí solo un producto de relevancia creciente al que se le reconoce un importante papel en la mejora de la oferta turística y como elemento de desarrollo económico de un territorio (Espeteix, 2004). Los turistas son, por tanto, protagonistas ineludibles de esta evolución; su estudio y comportamiento ha sido un campo de investigación necesario que ha ido cambiando a tenor de la diversificación, cada vez más amplia y acelerada, de la oferta y la demanda. Ahora bien, y como se constata en la bibliografía, en la elección y realización 
de un destino turístico intervienen principalmente factores económicos, sociales y psicológicos. La consideración de unos u otros ha llevado a la literatura académica a proponer una serie de tipologías bien por separado, bien interrelacionadas. Se asume, eso sí, que en el planteamiento de un viaje se combinan elementos como la capacidad adquisitiva, la personalidad, la moda social o las motivaciones. Y si bien diferentes y abundantes tipologías han dominado el marketing turístico en general, desde la pujanza que el turismo gastronómico ha adquirido, estas clasificaciones también se han ido trasladando al viajero gastrónomo. Así, Boyne et alter (2003) proponen una taxonomía según su reacción a la información gastronómica en cuatro tipos. Para los del tipo I, la gastronomía es una parte importante de la experiencia turística que los lleva a interesarse por el patrimonio gastronómico de una región. Los del tipo II no requieren de información sobre la gastronomía de forma exhaustiva, pero si se les proporciona, la tienen en cuenta. El tipo III no considera que la gastronomía sea un factor importante en la experiencia turística, aunque si durante su estancia ha disfrutado de una experiencia gastronómica, es muy probable que desee más experiencias de este tipo. Por último, lo consumidores del tipo IV no se interesan por la gastronomía.

Por su parte Hjalager (2002), basándose en Cohen (1984), plantea una categorización que describe sociológicamente los distintos perfiles de turista gastronómico: existencial, experimental, recreacional y de distracción. El primero gusta de experiencias gastronómicas en las que exista un componente importante de aprendizaje, esto es, de conocimiento de la cultura gastronómica de un destino, por lo que prefiere los restaurantes donde van los habitantes del lugar. El experimental sigue las últimas tendencias en la moda gastronómica -ingredientes, técnicas culinarias, recetas-y simboliza su estilo de vida a través de la comida y la bebida, por lo que consume restaurantes y locales de diseño innovador. El turista recreacional es el más conservador; busca comida y bebida similar a la de su lugar de origen; la gastronomía no significa un factor importante a la hora de escoger un destino. Por último, el turista de distracción pretende relajarse y escapar de la rutina diaria que supone el hacer la compra o cocinar; elige los restaurantes de franquicias, familiares y de platos sencillos, sin darle excesivo valor a la calidad.

Las que sí parecen prosperar son las investigaciones en torno al análisis motivacional de los turistas que emprenden viajes impulsados por un deseo de experimentar con los alimentos (Cetin \& Bilgihan, 2015; Mak et alter, 2012; Kivela \& Crotts, 2006). Grosso modo, el turismo gastronómico es una modalidad en la que la comida es uno de estímulos principales ( $\mathrm{Su}, 2013)$, pero también aquella en la que habría una motivación secundaria y es la de considerar la oferta culinaria, aunque no haya sido la razón principal del viaje (Quan \& Wang, 2004). La diversidad de estudios sobre las motivaciones culinarias queda sintetizada en dos categorías principales (Mak et alter, 2012): las que atañen a dimensiones simbólicas (aprendizaje de la cultura local, experiencia y emoción, autenticidad, prestigio) y dimensiones obligatorias (preocupación por la salud, necesidad física, etc.).

En efecto, el turismo culinario es algo más que comer; es una experiencia cultural (de aprendizaje), pero también un atractivo sensorial (la búsqueda del placer a través del gusto, del olfato, del tacto), una preocupación por la salud (en tanto se relaciona con el bienestar), así como una necesidad de prestigio (la gastronomía se hermana con el lujo cuando se ansía degustar la alta restauración) (Ellis et alter, 2018); pero de lo que no hay duda es de que está adquiriendo importancia en las decisiones de los viajeros y turistas. Las cifras lo avalan: según el $4^{a}$ Foro Mundial de Turismo Gastronómico de la Organización Mundial de Turismo del 2018, un 40\% del total el gasto turístico mundial se realiza en gastronomía. Para España, el informe de Dinamiza del año $2017^{2}$ cifra en un $76,2 \%$ aquellos que han realizado algún viaje con la intención de disfrutar de la gastronomía; de estos, el 62,4\% afirman que influye en gran medida en la elección del destino. Pero además, existe un $28,7 \%$ de la demanda total, denominado turista gastronómico puro, cuyo fin único es disfrutar de la gastronomía.

Por su parte, la consultora The Blueroom Project revela que una de las principales conclusiones del estudio del año $2018^{3}$ es que los productos de turismo gastronómico son reservados tanto por mujeres como hombres que buscan lo auténtico del destino a través de la comida y la bebida, destacando entre las actividades más atractivas los tours gastronómicos con visitas a mercados, fábricas, granjas y productores de comida (60\%); los eventos gastronómicos y enogastronómicos (29\%); la compra de productos locales (27\%); los actos relacionadas con la cocina (19\%); las ferias enogastronómicas (15\%) y la degustación los restaurantes de renombre (4\%). Asimismo, describe al turista gastronómico como un viajero que busca la autenticidad de los lugares que visita, a través de la comida y la bebida (58\%), un turista que sigue las nuevas tendencias del turismo cultural (25\%) y una persona que asocia el valor de la gastronomía al sentido de socializar e intercambiar experiencias (17\%). 
Así pues, y según las tipificaciones vistas con anterioridad, los turistas del tipo I de Boyne y los dos primeros de Hjalager —existencial y experimental_, resultarían ser los más interesados por las nuevas tendencias culinarias pero también, y en un amplio porcentaje, por la búsqueda de la autenticidad y el conocimiento de los productos que integran el patrimonio gastronómico de un territorio; de forma que algunas políticas turísticas en España, que recientemente han comenzado a considerar la gastronomía como recurso diferenciador para sus destinos, mantienen en sus estrategias de desarrollo este producto turístico como uno de los más viables y dinámicos del sector.

Así se aprecia a través de programas y acciones promocionales, que coadyuvan además a la diversificación y desestacionalización. Una de estas iniciativas reside en la creación de los clubs de producto, de los que el gastronómico destaca como elemento de singularidad. Ese es el caso de Saborea España ${ }^{4}$, un club de producto formado por un conjunto de empresas e instituciones de ámbito nacional - Federación Española de Hostelería, Asociación Española de Destinos para la Promoción del Turismo Gastronómico, Euro-Toques (Organización Europea de Cocineros), Federación de Cocineros y Reposteros de España y Paradores de Turismo-, cuyo objetivo principal es generar una oferta exclusiva y diferenciadora de producto turístico, cohesionada y unida bajo una marca determinada. No en vano, Saborea España es un reflejo de las tendencias y motivaciones de aquellos viajeros que buscan conocer, experimentar y degustar productos y elaboraciones culinarias autóctonas y dotadas de originalidad, creatividad y autenticidad, más en armonía con el patrimonio cultural de un territorio. Y este ha sido precisamente el objetivo de nuestro trabajo: observar los atributos que se encuentran en la oferta comunicativa de los destinos agrupados en este organismo para comprobar, o no, si la simplicidad (como se entiende en esta investigación) se está consolidando como una tendencia en el turismo gastronómico.

\subsection{Creatividad y gastronomía}

La creatividad consiste en alterar o modificar métodos preestablecidos; es la capacidad de resolver un problema cotidiano o extraordinario, con soluciones distintas a las habituales capaces de cambiar los procesos tradicionales de acción. La cocina creativa tiene que aportar frescura, originalidad e innovación; debe provocar en el comensal no solo placer al gusto, sino que también debe combinar sensaciones sensoriales distintas, y todo ello con la intervención de elementos desconocidos hasta el momento. Abundando en esta idea, Romo (1997) señala que la creatividad es una forma de pensar, cuyo resultado posee a la vez novedad y valor. Para Ferran Adrià, la experiencia gastronómica derivada de una cocina creativa "podría llamarse 'intelectual' por las razones técnicas, por lograrse mediante métodos culinarios diferentes a los convencionales y que producen nuevas formas de expresión del cocinero o artista, así como de admiración o disfrute por parte del comensal o público" (en Magallón, 2013: 3). Por su parte, y según Slavich et alter (2014: 30), la alta cocina se localizaría entre los sectores que aúnan la creatividad con el trabajo repetido y la estandarización al objeto de reproducir bienes creativos.

El consenso, empero, se logra al afirmar que una tendencia culinaria en tanto busca ser una primicia requiere de propuestas creativas que alimenten la necesidad, intrínseca al ser humano, de novedad; puede existir un momento en el que la sociedad necesite de una nueva respuesta (creativa) a una determinada demanda por cuestiones de moda o de carencia, lo que provoca la salida al mercado de un estilo gastronómico novedoso, provocador, atrevido y pleno de significado; esto es, y expresado de forma tautológica, el carácter novedoso es necesario para una nueva propuesta.

A propósito del concepto de novedad, partimos del trabajo de Romero Elías quien estudió su necesidad en los seres humanos y destacó las investigaciones de Kashdan y Silvia (2009), que sostienen que las personas están equipadas para explorar y adaptarse a las novedades que el entorno presenta; se precisa, pues, de una evolución constante para sobrevivir; de forma que los sistemas que no se renuevan tienden a agotarse y a desaparecer. Cabe destacar la predisposición con la que el ser humano se enfrentas a dichas novedades, pues, aunque haya una voluntad genética a disfrutar con los cambios (Di Domenico \& Ryan, 2017; Ekelund, Lichtermann, Järvelin \& Peltonen, 1999; Gallagher, 2011), la circunstancia de cada individuo forma las actitudes hacia lo nuevo. En este sentido, la formación y el conocimiento culinario son provechosos (aunque no imprescindibles) para que esta necesidad de novedad sea plenamente satisfecha, así como para que el individuo colme su curiosidad.

Por su parte, la simplicidad es clave en el desarrollo de esta investigación ya que se postula como una nueva corriente dentro de los procesos creativos de la restauración española. A la pregunta ¿es 
creativa la simplicidad? podría responderse con un ejemplo clave, aunque no gastronómico, como sería el diseño del metro de Londres de 1933, cuando el ingeniero Henry Beck desarrolló un mapa basado en el sistema de planos de electricidad; a raíz de esto, Londres es la única metrópoli que se conoce por el mapa del metro, no por el geográfico. Las líneas verticales, horizontales y diagonales a las que se reduce el diseño de un mapa de metro resuelven a la perfección la complejidad de un mapa tradicional. Es innovador, simple y lleno de significado; además es vigente y cualquiera es capaz de entenderlo sin saber más allá de lo que se le presenta, sin tener que leer explicaciones ni conceptos de gran complejidad para un usuario lego.

\subsubsection{La simplicidad como propuesta creativa gastronómica}

Tal y como se planteó en otro trabajo, el objetivo de la simplicidad en la cocina busca que un solo producto abarque cualidades y características capaces de emocionar al comensal (Fernández-Poyatos, Aguirregoitia-Martínez \& Bringas, 2019); lo que se obtiene, en general, a través de procesos complejos (fig. 1). Este método de trabajo radica en despojar al producto de lo innecesario y lograr lo específico, lo que le es propio y le diferencia de otros; se procura redimir al producto de ingredientes triviales e incorporar aquellos relevantes para dotar al plato de fuerza, carácter y personalidad. O como certeramente expresó Santi Santamaria (2012: 58) "Hay que promover una cocina donde la síntesis sea un valor, donde la sencillez sea un forma de expresión para hacer comprender a la sociedad el arte de la cocina". Esa emancipación de lo prescindible forma parte de uno de los procesos creativos más complejos: la simplicidad que, además de ser una cualidad muy sugestiva para el comensal, ya que alienta la fuerza de lo reconocible, se ha transformado en un proceso estratégico para que los cocineros afronten sus complejidades: "Lo sencillo es tan sencillo, tan sencillo, que es complicado" (Gueyu Mar, 2018). Un proceso de liberación vinculado con la culminación del conocimiento: saber para reducir, sostiene Maeda (2007). Y así, al reclamar la simplicidad como proceso creativo, se persigue dotar de valor la elaboración culinaria.

\section{Figura 1: Puro champiñón "Bagá": crema de Portobello crudo, natural laminado y deshidratado.}

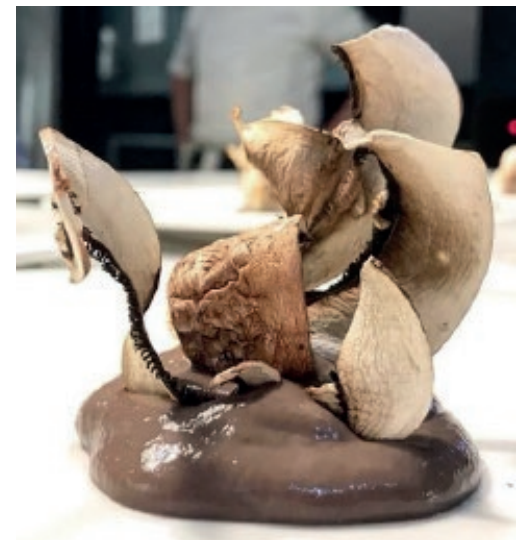

https://bagagastronomico.com/?p=1225.

Es preciso entonces abordar el concepto de simplicidad dentro de la experiencia gastronómica; para ello se retomará el concepto de pregnancia a partir de la Teoría de la forma de la Gestalt, que considera la percepción como un proceso fundamental de la actividad mental, en el que el individuo selecciona la información relevante que le ayudará a generar una representación mental. A esta selección de datos se le denominan categorías de organización, entre las que se encuentra la Ley de pregnancia, que consiste en atraer la atención del observador a través de la simplicidad. Un ejemplo ilustrativo se aprecia en las figuras 2-3 y 4-5, donde se ha prescindido de los elementos innecesarios en la ejecución del plato y se han mantenido solo los que ayudan al comensal (dos, tres o cuatro elementos, colores o texturas...) a interpretar la experiencia gastronómica. 
Figuras 2-3: (de izda. a dcha.). Cigala, cebolla roja y jugo de lombarda. Plato de bonito, de Nerua.
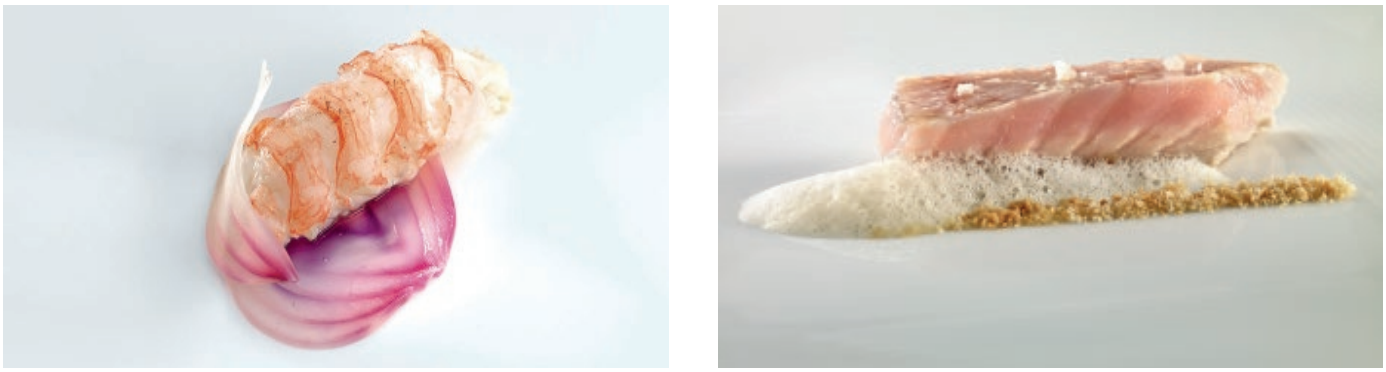

http://www.neruaguggenheimbilbao.com.

Figuras 4-5: (de izda. a dcha.). Puntilla con almeja rubia y crema de alcachofas. Ancas de rana y pil-pil.
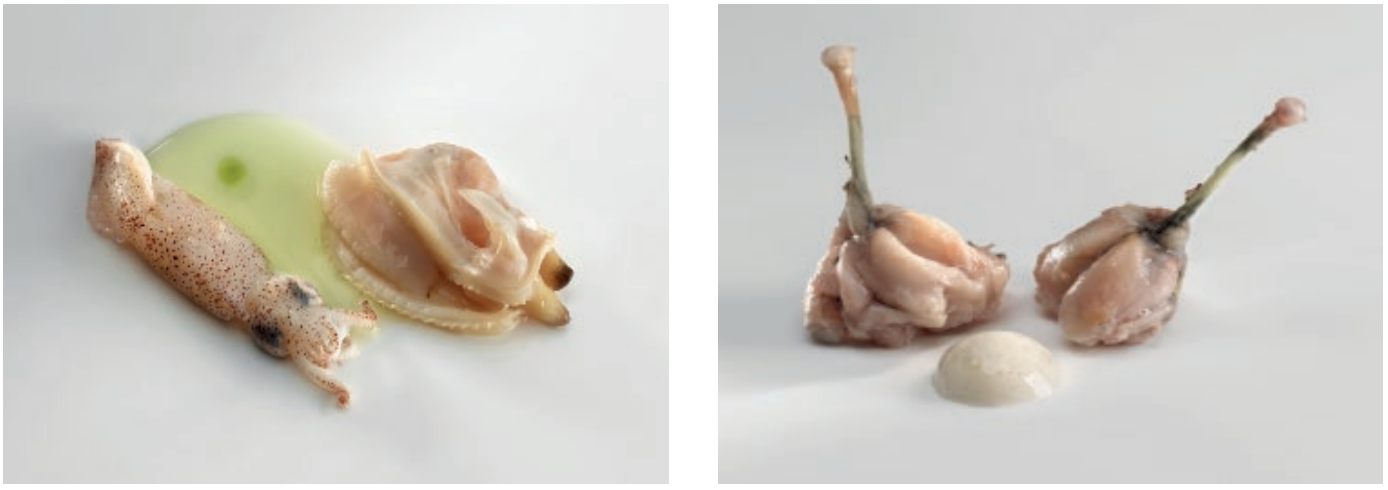

http://www.neruaguggenheimbilbao.com

Como sostiene Oteiza (en Bilbao, 2018), el vacío pregnante, lleno de significado, es el resultado de la materialización de una idea. Se reconoce, y se asume, que ante una forma inconclusa el ser humano es capaz de imaginar, de completar, lo que aún no existe. Trasladar este proceso a la cocina permitiría interpretar que cuando un cocinero elimina elementos o procesos de un plato en el que está trabajando, provoca en el comensal nuevas posibilidades de interpretación.

En ello ahonda Oteiza al afirmar que "la pregnancia de un boceto en curso, consiste en que tras una fase de acumular expresión en la obra, el artista pasa a un fase distinta, eliminando material de la obra. Sucede que a veces la obra responde a esa acción potenciando su significado" (Bilbao, 2018: 123-124), de forma que lo suprimido queda reemplazado por un conjunto abierto de posibilidades: eliminar para ver crecer. Según esto, la inicial exégesis del profesional ante el proceso creativo de un plato quedaría vinculado al trabajo más técnico y racional. Es preciso ahora recordar que los estudios sobre gastronomía se han centrado en enseñar a analizar la técnica, sin observar la parte más sensitiva vinculada a lo emocional. Esto último no ha de interpretarse como una crítica a los modelos formativos, ya que la disciplina y el conocimiento de la técnica son necesarios para abordar con éxito el proceso creativo, sino lo que con acierto respaldó Santamaria: el cocinero "tiene que dominar ciertas técnicas hasta el punto de poder alejarse de ellas para encontrar caminos personales para construir su propio mundo, su propio lenguaje" (2012: 258). Resulta entonces que, además de la técnica, y ya en el proceso creativo, los cocineros y cocineras precisan de un gesto emotivo que dote al plato de mayor personalidad y sensibilidad; un gesto que se integre con el entorno — paisaje, sociedad, identidad culinaria—, con el verbo y, en fin, con el concepto global. Desde esta perspectiva, que hacemos nuestra, ese gesto — ese 
acto- ha de estar relacionado con el arte de suprimir para que, así, sea el producto el que hable (Fernández-Poyatos, Aguirregoitia-Martínez \& Bringas, 2019).

Lo resume bien Maeda al declarar, desde una aproximación más técnica, que "la auténtica simplificación se obtiene cuando es posible reducir las funciones de un sistema sin sufrir demasiadas penalidades" (2007: 2). Una vez que se ha decidido qué se va a suprimir, Maeda se cuestiona si eliminar es el término adecuado, y lo que propone es la tríada estilizar-omitir-integrar.

El primero - estilizar - implica más complejidad en un producto que, en un primer contacto, no promete demasiado. De hecho, una cocina más primaria y tradicional puede conllevar una complejidad más artística y emocionante que la mezcla de ingredientes más inusitada. En cuanto al acto de omitir, se supone que, una vez descartados todos aquellos elementos que no enriquecen la propuesta, se ha de volcar en el resto toda la complejidad de la técnica para alcanzar el objetivo del cocinero. Finalmente, el acto de la integración expresa que la propuesta gastronómica debe componerse de las materias primas excelentes y técnicas de elaboración adecuadas para lograr cautivar a nuestro público. Se trata de que el producto final sea capaz de atraer y emocionar a aquellos que lo van a consumir: sólo así el producto podrá erigirse en el objeto-protagonista de la elaboración.

Dentro de esa cocina más primaria y tradicional y partiendo del recetario tradicional, —que contiene un grado de fascinación alto para aquellos que la practican: descubrir antiguas recetas para luego transformarlas en nuevas versiones más refinadas, técnicamente impecables y por encima de todo innovadoras-, se ha convertido en el camino creativo de muchos cocineros y cocineras españolas. Esta corriente defiende la identidad local gastronómica como algo propio y con necesidad de evolucionar por nuevos caminos creativos e interpretativos. "Por otra parte los genios de la alta cocina vasca como Juan Mari Arzak y Martín Berasategui predican la imperiosa necesidad de volver la vista a los proveedores artesanos, a la despensa campesina y cercana, a esos productos que regalan sabores genuinos y sin los cuales ninguna cocina clásica o vanguardista es posible" (Hernando, 2018: 2). Por todo ello, uno de los grandes retos de la gastronomía actual es recuperar el carácter local e identitario; sin olvidar la necesidad de novedad, evolución y creatividad propia de la cocina actual. En el trabajo de simplificación y vuelta a la cocina tradicional nos encontramos con el proceso de eliminación - considerado innecesario por muchos cocineros y aplaudido por otros-, pero también con el de una euforia hacia una fusión desmedida y totalmente impersonal de las cocinas más globales.

La búsqueda de una identidad gastronómica que rebase el tiempo, pero que también congregue la cocina tradicional con la vanguardista, converge cada vez más con una cocina de producto más simple, esto es, una cocina ligada a la naturalidad, a la autenticidad y a las costumbres. Una cocina que busca el laboratorio como un medio, como una herramienta que la dote de más sabor, que la lleve a conocer a través del sabor a fin de admirar la aparente simplicidad con la que se trata el producto; esto es, se busca cambiar el paradigma de la cocina tradicional mediante el conocimiento, el estudio y el saber, lo que significa (podría ser) alejarse del sentido común como herramienta histórica de la cocina. Este movimiento, seguido por relevantes cocineros, puede estar contribuyendo a redefinir el concepto de identidad hacia una versión ampliada, renovada y sabia que pueda ser un sugerente atractivo para un público gastrónomo más reflexivo o más curioso; una tendencia enmarcada en un espacio donde tradición e innovación se entrelazan para satisfacer la necesidad del cliente actual.

En la figuras 6-7; en la de la izquierda, se observa el tradicional talo del País Vasco, hecho con una base de maíz y cuya diferencia principal frente al taco mexicano es que su maíz no está nixtamalizado, de manera que su textura es mucho más quebradiza y arenosa. Sobre él se añade un trozo de chistorra, chorizo de la región bastante más fino de lo habitual y fresco; sus ingrediente principales son el cerdo y el pimentón. En la imagen de la derecha, el tartar de chorizo del restaurante Etxebarri: una base de maíz liofilizado y sobre él, un tartar de chorizo semicrudo elaborado con las partes más nobles del cerdo ibérico: el secreto y la presa. Además, se condimenta con pulpa de pimiento choricero de Guernica, una localidad del País Vasco, lo que suaviza y dulcifica el resultado final. Esta reinterpretación representa la evolución hacia la perfección de un plato muy popular, donde encontramos: materia prima de primera calidad, producto local, conocimiento y saber hacer. Por otro lado, en la imagen siguiente (figuras 8-9), se presentan las tradicionales y reputadas Kokotxas al pil-pil; a la izquierda, en su versión más clásica, y a la derecha, una interpretación más vanguardista del cocinero Josean Alija del restaurante Nerua; técnicamente son mucho más complejas que las clásicas en cuanto a su elaboración, sin embargo, el resultado final se antoja más sencillo, sutil y delicado. 
Figuras 6-7: (de izda. a dcha.). Talo tradicional vs Talo "Etxebarri”.
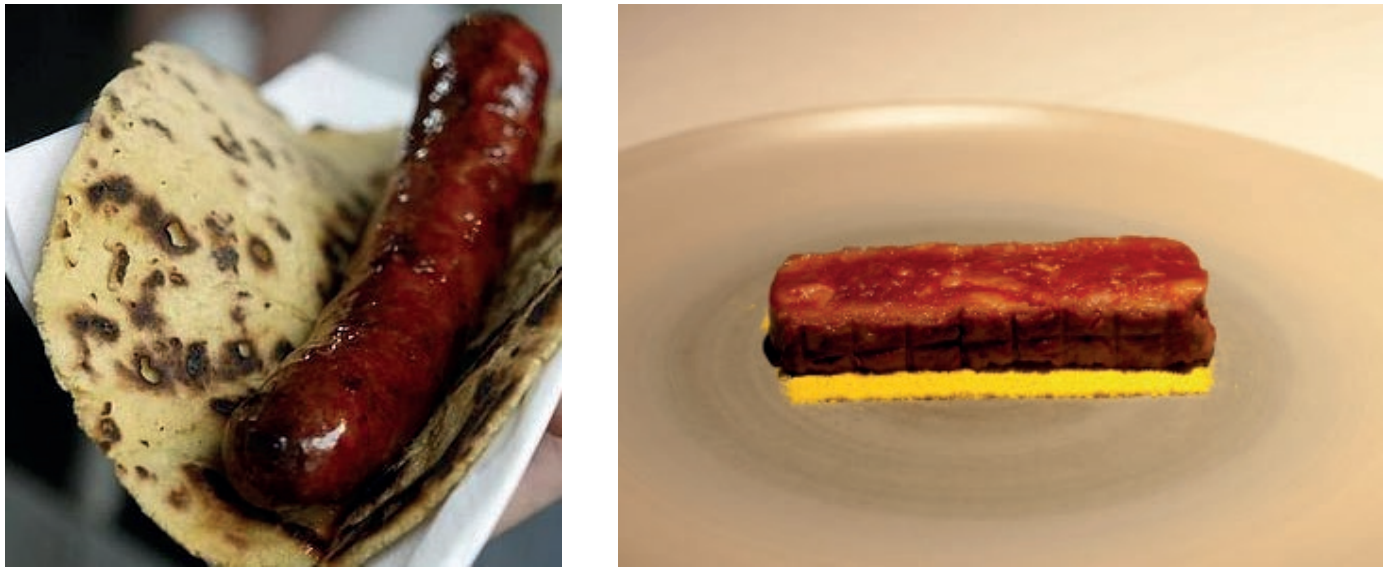

https://www.google.es

Figuras 8-9: (de izda. a dcha.). Kokotxas al pil-pil vs kokotxa al pil-pil "Nerua”.
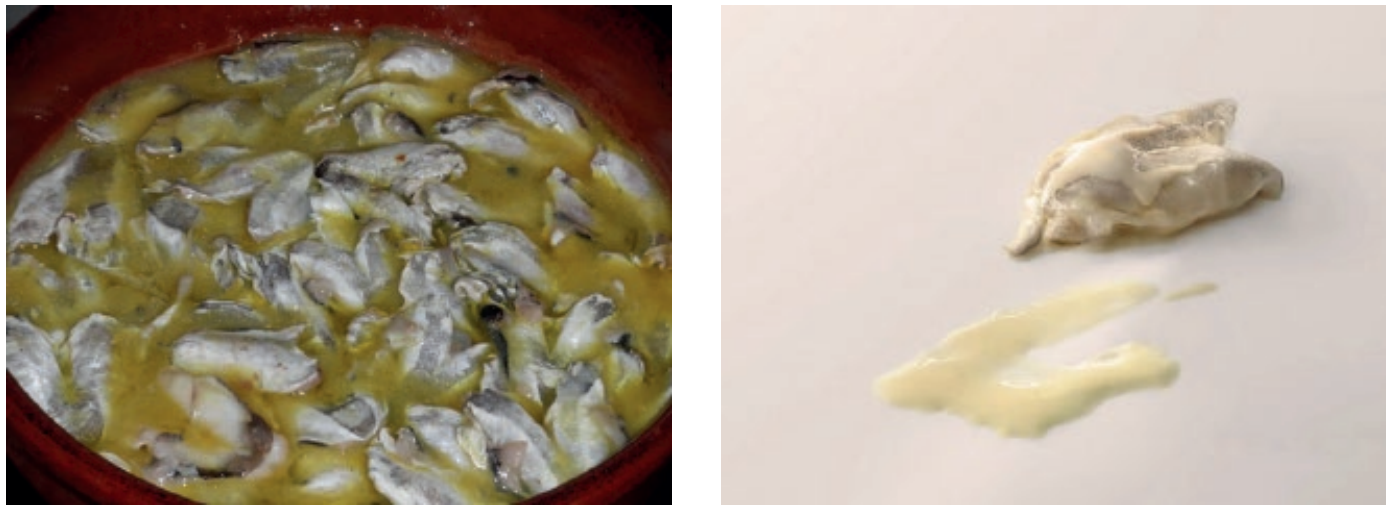

https://www.google.es y http://www.neruaguggenheimbilbao.com.

Estéticamente, incluso, pueden resultar de una sencillez ofensiva, tanto en lo visual como en el paladar; el conocimiento nos hace ver que, en lo que a ejecución de refiere, su complejidad técnica es abrumadora. Ambas se llevan a cabo con una selección de materia prima excepcional, la combinación de técnicas empleadas en su ejecución es vanguardia en estado puro, toda vez que el aprendizaje necesario para llevar a cabo ambas elaboraciones es altísimo. Saber interpretar clásicos de la cocina tradicional a través de una simplicidad solo aparente y conseguir emocionar al comensal no es tarea fácil. Estas tendencias gastronómicas suponen un reto para los cocineros y una novedad para los comensales, que son capaces de recorrer cientos de kilómetros para probar las novedades presentadas, para saciar su hambre emocional y vivir una experiencia que va más allá del acto fisiológico de comer, esto es, viajar para conocer, aprender o sentir; podría ser, quizá, lo que Adorno y Horkheimer (1979) denominaron cultura del entretenimiento. Los turistas (gastrónomos, o no) darán sentido a sus actos y decisiones si logran aquello que los ha impulsado a iniciar una peripecia turística. La cuestión sería, entonces, descubrir si en el ámbito gastronómico la simplicidad — tal y como la hemos expuesto aquí-, es un atributo ofrecido a viajeros y turistas, cuya motivación principal, o al menos bastante relevante, es la culinaria. 


\section{Metodología}

En una primera fase de la investigación, y planteada la hipótesis de la simplicidad y su proceso creativo como una tendencia posible para el turismo gastronómico en España, se inició la recopilación y selección de hechos; se abordó entonces un análisis de discurso que, en general, "se inscribe en lo que podríamos denominar el saber cualitativo, formando parte de lo que Valles llama el paradigma interpretativo" (Santander, 2011). Dicho análisis, vinculado en este caso a la revisión bibliográfica, pretende interpretar para después relacionar conceptos tales como la simplicidad o el proceso creativo estudiados en otras disciplinas —arte, psicología, ingeniería industrial... - , y poder así vincularlos con la simplicidad en tanto corriente gastronómica. Se espera con ello contribuir al conocimiento de una disciplina que se ha ido conformando de modo algo apresurado en los últimos años.

En una segunda fase, y debido al reconocimiento, a la importancia y al incremento constante de la gastronomía en España y a la conveniencia de investigaciones al respecto, el objetivo es reconocer cómo la simplicidad, entendida como resultado de un proceso creativo, se está implantado a través de valores como la sencillez, la tradición y la materia prima (excelente) en los discursos de los destinos turísticos que se integran en la entidad Saborea España. Se ha seleccionado este organismo porque fue creado por el Ministerio de Industria, Turismo y Comercio (2009) para atraer turistas hacia nuestro país debido al interés de nuestro patrimonio y experiencia gastronómicos. Su fin es potenciar el turismo y la gastronomía; para ello, pretenden transformar el producto gastronómico en una experiencia única y especializada de alto valor. Está integrada por veintiún destinos: A Coruña, Badajoz, Cambrils, Ciudad Real, Dènia, Gran Canaria, Lanzarote, Logroño, Madrid, Salamanca, Santa Cruz de La Palma, Segovia, Sevilla, Tenerife, Toledo, Tudela, Trujillo, Valencia, Valladolid, Vinaròs y Zaragoza ${ }^{5}$ (tabla 1). Lo que significa que numerosas áreas comunitarias del país están representadas aquí; además, entre sus funciones destaca la de darlos a conocer en mercados europeos para lo que realiza acciones promocionales entre las que sobresale la de divulgar el concepto de la "tapa", una de las ofertas culinarias de mayor fortaleza y atracción del nuestra culinaria.

\section{Tabla 1: Destinos gastronómicos en Saborea España}

\begin{tabular}{|c|l|}
\hline \multicolumn{1}{|l}{ Destinos } & \multicolumn{1}{|c|}{ Webs } \\
\hline A Coruña & http:/tastingspain.es/destinos/a-coruna/ \\
\hline Badajoz & http://tastingspain.es/destinos/badajoz/ \\
\hline Cambrils & http//tastingspain.es/destinos/cambrils/ \\
\hline Ciudad Real & http:/tastingspain.es/destinos/ciudad-real/ \\
\hline Dènia & http:/tastingspain.es/destinos/denia/ \\
\hline Gran Canaria & http://tastingspain.es/destinos/gran-canaria/ \\
\hline Lanzarote & http:/tastingspain.es/destinos/lanzarote/ \\
\hline Logroño & http:/tastingspain.es/destinos/lanzarote/ \\
\hline Madrid & http://tastingspain.es/destinos/madrid/ \\
\hline Salamanca & http://tastingspain.es/destinos/salamanca/ \\
\hline Segovia & http:/tastingspain.es/destinos/segovia/ \\
\hline Sevilla & http://tastingspain.es/destinos/sevilla/ \\
\hline Tenerife & http://tastingspain.es/destinos/tenerife/ \\
\hline Tudela & http://tastingspain.es/destinos/tudela/ \\
\hline Trujillo & http:/tastingspain.es/destinos/trujillo/ \\
\hline Valencia & http://tastingspain.es/destinos/valencia/ \\
\hline Valladolid & http://tastingspain.es/destinos/valladolid/ \\
\hline Vinaròs & http:/tastingspain.es/destinos/vinaros/ \\
\hline Zaragoza & http:/tastingspain.es/destinos/zaragoza/ \\
\hline &
\end{tabular}

Elaboración propia 
Una investigación previa (Fernández-Poyatos, Aguirregoitia \& Bringas, 2019), que ha inspirado la actual, observó la relevancia de esta tendencia en la gastronomía española. Entre otras cuestiones, se puso de manifiesto cómo la alta cocina utilizaba la identidad gastronómica en sus recursos comunicativos, para lo que se analizaron seis parámetros: materia prima, especialización, innovación, investigación, tradición y simplicidad. En esta ocasión, nos hemos preguntado, en primer lugar, por la presencia que la simplicidad tiene para los destinos turísticos referidos, integrando en ella los conceptos de sencillez, tradición y materia prima, ya que la investigación gastronómica los destaca como relevantes en las motivaciones de los turistas y viajeros gastrónomos. Asimismo, y en segundo lugar, se ha optado también por observar en el análisis qué otros atributos aparecen con cierta frecuencia en sus discursos comunicativos.

Después de revisar en epígrafes anteriores la literatura sobre el turismo gastronómico, las motivaciones de los viajeros, la simplicidad y la creatividad, se han examinado los conceptos referidas en los mensajes contenidos en el portal de los destinos turísticos que se integran en Saborea España. El objetivo es observar si la simplicidad es un elemento que se utiliza en los discursos para añadir valor a la gastronomía de un destino, así como conocer qué otros predominan en ellos. De todo ello, consideramos que podría aventurarse si la simplicidad es, o no, una tendencia para el turismo gastronómico.

\section{Resultados}

Lo más relevante es la ausencia del término simplicidad en los portales revisados; ahora bien, el resto de los elementos analizados sí están presentes en todos menos en el de Logroño, que brinda una oferta más diversificada y centrada en la enología.

El concepto que predomina en diecisiete de ellos (89,2\%) es el de tradición, expresado bajo diversos grupos léxicos: cocinas, embutidos y elaboraciones tradicionales; sabia tradición, lugares que reinventan la tradición, gastronomía tradicional y mezcla o fusión de tradición e innovación y modernidad.

Aunque con escasez, la materia prima es el segundo de los parámetros más usados. Se constata en cinco ocasiones $(26,3 \%)$ : materias primas de calidad, ricas y tradicionales, que, como se indica en Segovia, se requiere que cumpla unas condiciones para revalorizar los productos. Sin embargo, se ha considerado que la referencia a este concepto podría hallarse también en aquellas expresiones que califican y reivindican los productos como autóctonos, de proximidad, locales, de la tierra, etc.; de forma que se incrementarían en dieciséis $(84,2 \%)$ los destinos que apelan a este atributo.

En cuanto a la sencillez, sólo se advierte en tres destinos (15,7\%): en A Coruña, sus elaboraciones sencillas realzan el valor de la materia prima; Ciudad Real presume de una excelente y sencilla gastronomía y Dènia elabora sus reputadas gambas con sencillez "que, por sí mismas, lo tienen todo".

Respecto a qué otros atributos comunicativos se aprecian en estos discursos, resalta el interés de algunos destinos por reivindicar su sincretismo culinario (42,1\%): bien por la interacción de distintas culturas (Badajoz), bien por la existencia de recetarios únicos por la mezcla de Europa, Latinoamérica y África (Gran Canaria) o bien porque su cocina (Sevilla) es una mixtura de los pueblos judíos, romanos, cristianos y latinoamericanos.

Asimismo, las nuevas tendencias y la cultura de la innovación $(52,63 \%)$ que, unida a la tradición, se reivindica como la vía necesaria para el progreso culinario: una cocina local, de producto que convive con la de vanguardia (A Coruña) o aquella que aúna tradición e innovación en Dènia.

Hay que destacar, por último, los elementos discursivos que buscan otorgar valor a los destinos gastronómicos como son las menciones a los restaurantes con estrellas Michelin $(26,3 \%)$ y a las Denominaciones de Origen (D.O.) e Indicaciones Geográficas Protegidas (I.G.P.): un 26, 3\% del total. 
Tabla 2: Elementos comunicativos en destinos gastronómicos de Saborea España

\begin{tabular}{|c|c|c|c|c|c|c|c|}
\hline \multirow{2}{*}{$\begin{array}{l}\text { Destinos } \\
\text { Turísticos }\end{array}$} & \multirow{2}{*}{ Sencillez } & \multirow{2}{*}{$\begin{array}{l}\text { Materia prima } \\
\text { (producto } \\
\text { autóctono/ } \\
\text { proximidad/ } \\
\text { local/de la } \\
\text { tierra) }\end{array}$} & \multirow{2}{*}{ Tradición } & \multirow{2}{*}{$\begin{array}{l}\text { Sincretismo } \\
\text { culinario }\end{array}$} & \multirow{2}{*}{$\begin{array}{c}\text { Fusión } \\
\text { Vanguardia/ } \\
\text { Innovación/ } \\
\text { Tradición }\end{array}$} & \multicolumn{2}{|c|}{$\begin{array}{l}\text { Valores } \\
\text { añadidos }\end{array}$} \\
\hline & & & & & & $\begin{array}{l}\text { DO } \\
\text { IGP }\end{array}$ & \\
\hline \multicolumn{8}{|l|}{ A Coruña } \\
\hline \multicolumn{8}{|l|}{ Badajoz } \\
\hline \multicolumn{8}{|l|}{ Cambrils } \\
\hline \multicolumn{8}{|l|}{ Ciudad Real } \\
\hline \multicolumn{8}{|l|}{ Dènia } \\
\hline \multicolumn{8}{|l|}{ Gran Canaria } \\
\hline \multicolumn{8}{|l|}{ Lanzarote } \\
\hline \multicolumn{8}{|l|}{ Logroño } \\
\hline \multicolumn{8}{|l|}{ Madrid } \\
\hline \multicolumn{8}{|l|}{ Salamanca } \\
\hline \multicolumn{8}{|l|}{ Segovia } \\
\hline \multicolumn{8}{|l|}{ Sevilla } \\
\hline \multicolumn{8}{|l|}{ Tenerife } \\
\hline \multicolumn{8}{|l|}{ Tudela } \\
\hline \multicolumn{8}{|l|}{ Trujillo } \\
\hline \multicolumn{8}{|l|}{ Valencia } \\
\hline \multicolumn{8}{|l|}{ Valladolid } \\
\hline \multicolumn{8}{|l|}{ Vinaròs } \\
\hline Zaragoza & & & & & & & \\
\hline
\end{tabular}

Elaboración propia

\section{Conclusiones}

Esta investigación considera la simplicidad —efecto de un proceso creativo- como una tendencia que está cada vez más presente en cualquier área del diseño en general, y de la gastronomía en particular. En España, la gastronomía se encuentra en un alto nivel creativo; no en vano, en las dos últimas décadas, ha sido reconocida tanto nacional como internacionalmente a través de numerosos premios y reconocimientos.

Gracias a este progreso, se están recuperando muchas cocina locales, pues uno de los valores más importantes de la simplicidad en la gastronomía es, precisamente, el uso de recursos, productos y técnicas históricas y propias. Una cocina de producto o más local no ignora los avances culinarios más modernos, sino que aplica métodos vigentes en la revolución culinaria moderna sin olvidar la tradición, el producto y la simplicidad de su ejecución. Esta tendencia podría provocar un incremento de turistas gastronómicos puros — su único fin es disfrutar de la gastronomía, viajar por y para ella— por encima del 28,7\% que cifra el informe de Dinamiza (2017), aunque también del 62,4\% de los turistas que declaran que influye en gran medida en la elección del destino. 
Asimismo, este trabajo aprecia que es conveniente ahondar en el conocimiento de la gastronomía desde diversas perspectivas. Por una parte, como proceso artístico, pues apenas existen estudios de factura cualitativa que, creemos, resultarían más reflexivos y proclives a provocar las ideas. Por otra, como recurso comunicativo para destinos turísticos que deseen poner en valor su patrimonio culinario y su realidad restauradora, sobre todo cuando esta se basa en la sencillez, la tradición y la calidad de sus materias primas; esto es, en aquellos elementos que, implícitamente, cimentan una cocina guiada por la simplicidad. Hay que superar, pues, las acepciones más populares de este concepto (simple, desabrido, sin dificultades) para relacionarlo con los procesos creativos propuestos por Oteiza y Maeda en torno al vacío pregnante y a la tríada estilizar-omitir-integrar para observar cómo es trasladado, con poca consciencia en ocasiones, a la cocina y a los discursos promocionales de los destinos turísticos bajo términos que podrían ser bastante similares. Un proceso creativo que reivindica, en bastantes discursos, la identidad local gastronómica a través de la recuperación de la cocina tradicional que acoge, eso sí, la innovación y la vanguardia culinaria.

Incentivar trabajos en esta línea redundaría en el conocimiento de nuestra gastronomía — tradicional y de vanguardia - , pero también en directrices y propuestas para que organismos públicos y entidades privadas conozcan mejor un sector en expansión a fin de implementar proyectos que deriven tanto en su recuperación como patrimonio de los territorios, como en acciones turísticas para dinamizar sus economías.

Precisamente, sobre la actividad investigadora en este ámbito, se han señalado los insuficientes estudios sobre la relación entre turismo y gastronomía que, desde la perspectiva gastronómica son aún más parcos, probablemente porque es esta una disciplina de corto recorrido académico en España -apenas un lustro-, de manera que es lógico que los estudios en esta área escaseen, máxime cuando se busca deliberar sobre conceptos culinarios como elementos comunicativos de atracción turística y no sobre laureados restaurantes que son objeto de un mayor interés. Desde esta óptica, los trabajos que pretenden buscar conexiones entre turismo y nociones como la simplicidad gastronómica son más inusuales, por no decir inexistentes; en efecto, no abordan el interés que pueden albergar técnicas o elaboraciones culinarias relacionadas con la simplicidad tal y como es entendida en nuestro trabajo, esto es, como una propuesta creativa, cuya base es la excelencia de la materia prima y la aparente sencillez del proceso empleado. La oferta a través de la promoción turística, en este caso a través del portal Saborea España, lo pone de manifiesto, aunque también, y en un repaso rápido, portales turísticos, responsabilidad de organismos públicos, que incluyen estos atributos en su discursos: producto de cercanía, kilómetro cero, calidad natural de las materias primas, productos frescos de la tierra, ... a la búsqueda de una cocina creativa y simple que, glosando a muchos, no tenga miedo a aliños ni a guarniciones lejanas o técnicas remotas; una cocina que conjuga tradición, saber y calidad pero, eso sí, si le viene bien al plato ${ }^{6}$.

El turista demanda cada vez más una oferta diversificada en la que lo culinario ocupa más y más espacio, pero ¿qué oferta culinaria resulta ser más atrayente?, ¿cuál demanda en mayor medida?, ¿la alta restauración y sus creaciones vanguardistas?, ¿las elaboraciones tradicionales y auténticas?, y ¿qué ha de entenderse por auténticas?, ¿excluyen estas últimas a la alta cocina?, ¿qué persiguen los viajeros en sus anhelos culinarios? Un panorama que se torna complejo por una demanda turística más diversificada, así como por la confluencia de varias generaciones de turistas: la más joven —los millenialls - se inclina por los productos locales, los pequeños restaurantes y la autenticidad, mientras que la cohorte demográfica anterior - la generación X y los baby boomers- persiguen la tradición y la calidad en su experiencia gastronómica ${ }^{7}$.

En cualquier caso, en lo que sí hay unanimidad es en asumir que la gastronomía es un recurso clave en la propuesta de valor y diferenciación de los destinos y en que el turismo gastronómico les brinda la oportunidad de construir un relato diverso, sugestivo y emocional para llegar a un cliente más exigente y variado.

Parece conveniente, pues, plantear estudios sobre los procesos y los atributos que se destacan en esta cocina y su pertinencia e interés para los viajeros y turistas, lo que obliga a abordar discusiones conceptuales del ámbito culinario. Una pequeña contribución ha sido este trabajo que aborda el análisis en los destinos que se integran en Saborea España, pues es un modelo representativo de la interrelación del territorio con la gastronomía que nos ha permitido observar cómo en su discurso promocional se interrelacionan la gastronomía y el turismo en torno al concepto de la simplicidad, es decir, como una tendencia para el turismo gastronómico.

Destinos como Dènia reflejan muy bien en su discurso lo que se afirma en esta investigación cuando, a propósito de la gamba roja, declara "su elaboración es sencilla. Por sí misma lo tiene todo. Ello no 
imposibilita que se experimente con nuevas recetas, que den un toque creativo al plato sin restarle protagonismo a su materia prima principal, la Gamba". Esto es, materia prima excelente y elaboración aparentemente básica, que añada valor y no reste: quitar para sumar.

Conscientes, o no, los profesionales de la cocina desarrollan un proceso creativo cuando apelan a la materia prima excelente, trabajada con técnicas sencillas (en apariencia) para lograr platos auténticos y originales; esto es, actualizan el concepto de simplicidad aquí considerado que, después, se manifestará y reivindicará en el discurso promocional para otorgar valor a su gastronomía y para atraer viajeros con interés de conocer y saborear la cultura local a través de su culinaria. Pueden ser esos grupos de turistas que Hjalager llama existenciales y experimentales, o aquellos de los que Boyne et alter dicen que se interesan por el patrimonio culinario de una localidad; esos buscadores, en suma, del sabroso placer de la cocina.

\section{Bibliografía}

Adorno, T. y Horkheimer, M. 1979. Sociológica. Madrid: Taurus.

Bauman, Z. 2007. Tiempos líquidos : vivir en una época de incertidumbre. Barcelona: Ensayo Tusquets Editores.

Beneyto, M. y Mateos C. 2018. Templos del producto. Barcelona: Planeta Gastro Editorial.

Bilbao, $\mathrm{M}^{\mathrm{a}}$. 2018. Entrevista de J. Luis Merino. http://www.fundacionendurance.com/cultura/entrevista-maria-bilbao/

Blueroom Project 2018. Estudio turismo gastronómico 2018. https://drive.google.com/file/d/1yq6ngVI4 RXrMmngEgZ5gmRkskHb0vZTL/view

Boyne, S., Hall, D. y Williams, F. 2003. "Policy, support and promotion for foodrelated tourism initiatives: a marketing approach to regional development", en Journal of Travel \& Tourism Marketing, 14 (3/4): 131-154. https://www.tandfonline.com/doi/abs/10.1300/J073v14n03_08

Cetin, G. y Bilgihan, A. 2015. "Components of cultural tourists' experiences in destinations. Current Issues in Tourism,

Cohen, E. 1984. "The sociology of tourism: Approaches, issues and findings", en Annual Review of Sociology, 10: 372-392.

Di Domenico, S. I. y Ryan, R. M. 2017. "The emerging neuroscience of intrinsic motivation: A new frontier in self-determination research", en Frontiers in Human Neuroscience, 11: 145.

http://dspace.umh.es/bitstream/11000/4132/1/Romero\%20El\%C3\%ADas\%2C\%20Mar\%C3\%Ada_TFM.pdf

Dinamiza. https://www.hosteltur.com/comunidad/nota/020591_tres-de-cada-cuatro-espanoles-viajan-motivados-por-la-gastronomia.html

Ekelund, J., Lichtermann, D., Järvelin, M. R. y Peltonen, L. 1999. "Association between novelty seeking and the type 4 dopamine receptor gene in a large Finnish cohort imple", en American Journal of Psychiatry, 156: 1453-1455. http://dspace.umh.es/bitstream/11000/4132/1/Romero\%20 El\%C3\%Adas\%2C\%20Mar\%C3\%Ada_TFM.pdf

Ellis A., Park E., Kim S. y Yeoman I. 2018. "What is food tourism?, en Tourism Management, $\mathrm{n}^{\circ}$ 68: 250-263.

Espeteix, E. 2004. "Patrimonio alimentario y turismo", en Pasos. Revista de Turismo y Patrimonio Cultural, 2, n 2: 193-213. https://doi.org/10.j.pasos.2004.02.016

Exceltur (2015). Índice sintético del PIB turístico español. https://www.exceltur.org/indice-sintetico-del-pib-turistico-espanol-iste/.

Fernández, G. y Ramos, Aldo G. 2010. "El patrimonio cultural como oferta complementaria al turismo de sol y playa. El caso del sudeste bonaerense". Argentina. Revista de Turismo y Patrimonio Cultural, 8, $\mathrm{n}^{\circ}$ 1: 139-149. https://doi.org/10.j.pasos.2010.08.011

Fernández-Poyatos, $M^{\mathrm{a}}$ D., Aguirregoitia-Martínez, A. y Bringas, N. 2019. "La cocina de producto: seña de identidad y recurso de comunicación en la alta restauración en España”, en Revista Latina de Comunicación Social, $\mathrm{n}^{\mathrm{0}} 74$.

Gallagher, W. 2011. New: Understanding our need for novelty and change. New York: Penguin.

García, A. y Alburquerque, F. J. 2003. "El turismo cultural y el de sol y playa: ¿sustitutivos o complementarios?", en Cuadernos de Turismo, 11: 97-105.

Giddens, A. 1991. Modernity and self-identity. Cambridge: Polity.

Hernando, A. 2018. Cocina creativa. Murcia CDT. http://www.cctmurcia.es/formacion/SPF20101452_M.pdf 
Hjalager, A.M. 2002. "A tipology of gastronomy tourism": 21-35. En Hjalager y Richards (eds), Tourism and Gastronomy, Londres y Nueva York: Routledge.

Kivela, J. y Crotts, J.C. 2006. "Tourism \& gastronomy: Gastronomy's influence on how tourist experience a destination", en Journal of Hospitality and Tourism Research, 30: 354-377.

KPMG. Enero 2019. La gastronomía en la economía española. Impacto económico de los sectores asociados. https://home.kpmg/es/es/home/sala-de-prensa/notas-de-prensa/2019/01/los-sectores-economicos-asociados-a-gastronomia-representa-33-por-cierto-pib-espana.html

Leal, $\mathrm{M}^{\mathrm{a}}$ P. 2011. "La diversificación del destino turístico a través del turismo gastronómico: el caso de Vilanova i la Geltrú (Barcelona)" en Pasos. Revista de Turismo y Patrimonio Cultural, 9 (1): 15-24. https://doi.org/10.25145/j.pasos.2011.09.0102

Maeda, J. 2007. Las leyes de la simplicidad. Barcelona: Gedisa Editorial.

Magallón, R.C. 2013. Creatividad Gastronómica: Adrià y su "Libertad para crear".

Mak, A.H.N., Lumbers, M., Eves, A. y Chang, R.C.Y. 2012 "Factors influencing tourist food consumption", en International Journal of Hospitality Management, 3: 928-936.

Medina, F.X. 2017. "Reflexiones sobre el patrimonio y la alimentación desde las perspectivas cultural y turística", en Anales de Antropología, 51: 106-113.

Ministerio de Industria, Energía y Turismo, Balance año turístico 2014. http://www.minetur.gob.es/es-es/ gabineteprensa/notasprensa/2015/documents/150121dossier\%20balance\%20tur\%C3\%ADstico\%20 2014.pdf

Quan, S. y Wang, N. 2004. "Towards a structural model of the tourist experience: an illustration from food experiences en tourism", en Tourism Management, 25: 297-305.

Restaurante Gueyu Mar. http://gueyumar.es/

Romero, M. 2016-2017. Analizando la importancia de la necesidad de novedad en la vida y en el ejercicio físico desde la teoría de la autodeterminación (Tesis de grado). Elche: Universidad Miguel Hernández.

http://dspace.umh.es/bitstream/11000/4132/1/Romero\%20El\%C3\%ADas\%2C\%20Mar\%C3\%ADa_TFM.pdf

Saborea España. http://tastingspain.es/

Santamaria, S. 2012. La cocina al desnudo. Barcelona: Planeta editorial.

Santander, P. 2011. "Por qué y cómo hacer Análisis de Discurso", en Cinta Moebio, 41: 207-224. www. moebio.uchile.cl/41/santander.html

Sengel, T., Karagoz, A., Cetina, G., Dincera, F.I., Ertugrala, S.M. y Balik, M. 2015. “Tourists' Approach to Local Food", en Procedia - Social and Behavioral Sciences, 195: 429 - 437.

Slavich, B., Cappetta, R. y Salvemini, S. 2014. "Creativity and the Reproduction of Cultural Products: the Experience of Italian haute Cuisine Chefs", en International Journal of Arts Management, $\mathrm{n}^{\circ}$ 16 (2): 29-71.

Stringfellowb, Lindsay, MacLaren, A., Maclean, M. O’Gorman, K. 2013. "Conceptualizing taste: Food, culture and celebrities", en Tourism Management, 37: 77-85. http://dx.doi.org/10.1016/j. tourman.2012.12.016

$\mathrm{Su}, \mathrm{C}$. 2013. "An importance-performance analysis of dining attributes: A comparison of individual and packaged tourists in Taiwan. Asia Pacific ", en Journal of Tourism Research, 18 (6): 573-597.

The Blueroom Project 2018. Estudio turismo gastronómico 2018. https://drive.google.com/file/d/1yq6n gVI4RXrMmngEgZ5gmRkskHb0vZTL/view

\section{Notas}

Exceltur (2018). https://www.exceltur.org/indice-sintetico-del-pib-turistico-espanol-iste/

Informe del grupo Dinamiza. https:/www.hosteltur.com/comunidad/nota/020591_tres-de-cada-cuatro-espanoles-viajanmotivados-por-la-gastronomia.html

3 Datos de la encuesta realizada a 180 profesionales de la industria turística, de los que 117 (el 65\%) son agentes de viajes o tour operadores. https://drive.google.com/file/d/1yq6ngVI4RXrMmngEgZ5gmRkskHb0vZTL/view http://www.fehr.es/promocion-gastronomica-fehr.html

Santa Cruz de La Palma y Toledo se han incorporado a la red Saborea España en enero de 2019 y todavía no cuentan con un portal propio, de manera que quedan fuera de nuestro estudio.

https://www.turismoasturias.es/gastronomia

KPMG, 2019.

Recibido:

Reenviado: 